\title{
Characterization of the Physicochemical Properties of the Micelle of the Novel Platelet Factor Receptor Antagonist, E5880
}

\author{
Yasuyuki AsAI* \\ Formulation Research Laboratory, Kawashima, Eisai Co., Ltd. \\ (1 Takehaya-machi, Kawashima-cho, Hashima-gun, Gifu 501-6195, JAPAN)
}

Edited by K. Tajima, Kanagawa Univ., and accepted December 1, 2002 (received for review September 20, 2002)

\begin{abstract}
The injectable formulation of E5880, a novel platelet factor (PAF) receptor antagonist, was developed. The physicochemical properties of E5880 micelles in the optimized formulation $(0.6 \mathrm{mg} / \mathrm{ml}$ of E5880, $0.1 \%$ citric acid, $10 \%$ lactose, $\mathrm{pH} 2.8)$ were characterized. The critical micelle concentration of E5880 was $0.09 \mathrm{mg} / \mathrm{ml}$, and the structure was spherical. The micelle size was $5.6 \mathrm{~nm}$. The number of the molecules per micelle was 46 . The micropolarity around the hydrocarbon region in the micelle was similar to that of isobutanol.
\end{abstract}

Key words: micelle, critical micelle concentration, structure, micropolarity

\section{Introduction}

Platelet activating factor (PAF), 1-alkyl-2-acetylglycerylphosphocholine, is a group of biologically potent active phosphoglyceride with actions more diverse than those of eicosanoids (1). PAF exhibits a variety of biological activaties including activation of platelets (2), neutrophilis (3), bronchoconstriction (4), hypermeability in perpheral veins (5), hypotensioin (6), and cardiac dysfunction (7). Because these biological activities of PAF are extremely potent, it is generally accepted that PAF is a mediator of inflammation (8) and plays important roles in the pathology of thrombosis, asthma or hypotension in shock (9-11). Consequently, it is expected that specific PAF receptor antagonists may be beneficial for the treatment of these diseases, and many efforts to develop potent and specific PAF antagonist have been made.

Several PAF antagonists, such as CV-3988 (12), CV6209 (13), SRI63-072 (14), U66985 (15) were synthesized and the biological activities were evaluated.
These compounds have hydrocarbon chains $\left(\mathrm{C}_{18: 0}\right)$ and are amphiphilic, indicating that some aggregates will be formed in aqueous media. They were dissolved in an aqueous medium and injected into animals for animals for evaluation of their biological activities; however, their physicochemical properties were not reported.

E5880, a newly synthesized PAF antagonist (Fig. 1), is more potent in PAF receptor binding than PAF (16). This compound is amphiphilic and it is expected to form the micelles in aqueous media. For the treatment of the above diseases, an injectable formulation would be extremely useful. In order to develop the injectable formulation, the clarification of the characteristics of the physicochemical properties for E5880 micelles is important for quality control in pharmaceutical dosage form.

In this study, in order to clarify the behavior of E5880 micelles in the formulation, the critical concentration for the formation of micelles was determined by surface tension measurements. The 'critical packing parameter' was determined and the size, structure and

\footnotetext{
*Correspondence to: Yasuyuki AsAI, Formulation Research Laboratory, Kawashima, Eisai Co., Ltd., 1 Takehaya-machi, Kawashima-cho,

Hashima-gun, Gifu 501-6195, JAPAN

E-mail: y2-asai@hhc.eisai.co.jp
} 


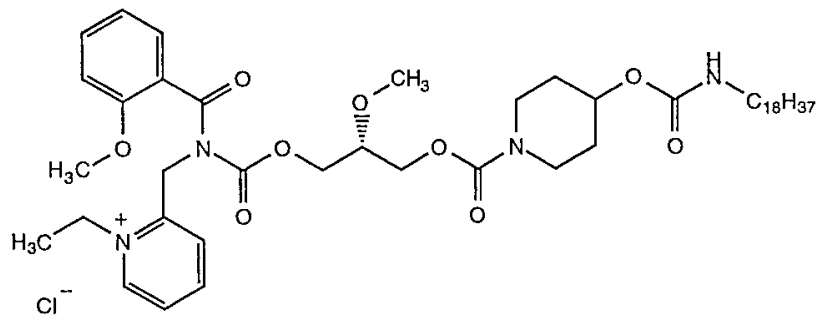

Fig. 1 Chemical Structure of the Novel Platelet Factor Receptor Antagonist, E5880.

the number of the molecules per micelles were calculated and compared with the results from dynamic and static light scattering. In addition, in order to obtain an information on the rigidity of the micelle, the micropolarity around the hydrophobic region of the micelles was determined by fluorescence techniques.

\section{Experimental}

\subsection{Materials}

E5880 was obtained from Eisai Chemical Co., Ltd. (Ibaraki, Japan). Its chemical purity was determined by HPLC method (99.8\%). Lactose was purchased from Mallinckrodt (Paris, KY), and citric acid was purchased from Kozakai-Seiyaku Co., Ltd. (Tokyo, Japan). Nile red (NR) was purchased from Lambda (Graz, Austria).

\subsection{Methods}

$2 \cdot 2 \cdot 1$ Determination of critical micelle concentration by measurement of surface tension

To determine the critical micelle concentration, the surface tension of E5880 formulated solution (0.1 $\mathrm{mg} / \mathrm{ml}$ citric acid, $10 \%$ lactose, $\mathrm{pH} 2.8$ ) was measured by Wilhelmy' s method using a surface tensiometer (model CBVP-A3, Kyowa Kaimenkagaku Co., Ltd., Tokyo, Japan) at $25^{\circ} \mathrm{C}$.

$2 \cdot 2 \cdot 2$ Determination of the molecular weight of the micelles

The molecular weight of the micelles in the solution $(0.1 \mathrm{mg} / \mathrm{ml}$ citric acid, $10 \%$ lactose, $\mathrm{pH} 2.8)$ was determined using static light scattering techniques. Measurements were carried out with the DLS-7000DL analyzer (Ohtsuka Electronics Co., Ltd., Osaka, Japan) at $25^{\circ} \mathrm{C}$. The results of the static light scattering measurements were analyzed according to the well-known equation (17):

$\left(K c / R_{q}\right)=\left[k^{\prime}(d n / d c)^{2} \times c\right] / R_{q}$

$$
=\left(1 / M_{w}\right) \times\left\{1+\left[16 \pi^{2} n_{0}{ }^{2} / 3 l_{0}^{2}\right]\left(R_{g}{ }^{2} \sin ^{2}(q / 2)+2 A_{2} c\right)\right.
$$

Where $K$ is the scattering coefficient, $R_{q}$ is the reduced scattering intensity of the solution in excess over the solvent at the scattering angle $q, k^{\prime}$ is the optical constant, $c$ is the weight concentration of the solution (in this case, $2 \mathrm{mg} / \mathrm{ml}$ ), $n_{0}$ is the solvent refractive index, $l$ is the wavelength in vacuum, $R_{g}{ }^{2}$ is the mean square radius of gyration, $A_{2}$ is the second virial coefficient (in this case, $A_{2}$ is almost equal to zero), and $M_{w}$ is the weight-average molecular weight of the system. All light scattering measurements were performed for scattering angle measurements of $30-150^{\circ}$. The refractive index increments $(\mathrm{d} n / \mathrm{d} c)$ of the micelles were determined individually with DRM-1020 (Ohtsuka Electronics Co. Ltd., Osaka, Japan) at $25^{\circ} \mathrm{C}$.

\section{$2 \cdot 2 \cdot 3$ Determination of the size of the micelles}

The size distribution of the micelles was determined by the dynamic light scattering (DLS) technique using a laser particle analyzer equipped with an Ar laser (Model DLS-7000DL, Ohtsuka Electronics Co., Ltd., Osaka, Japan) at $25^{\circ} \mathrm{C}$. The data were analyzed by the histogram method (18) and the weight-average size was evaluated.

\section{$2 \cdot 2 \cdot 4 \quad$ Measurment of zeta potential}

The zeta potential of the micelles in the buffer solution ( $\mathrm{pH} 2.8$ ) was measured at $25^{\circ} \mathrm{C}$ using an Ohtsuka Electronics (Osaka, Japan) model ELS-800 zeta potential analyzer. The data are presented as the mean values of triplicate measurements.

$2 \cdot 2 \cdot 5$ Determination of the micropolarity around NR in the hydrocarbon region of the E5880 micelles

The micropolarity of hydrocarbon regions in E5880 micelles was determined using a fluorescence technique (probe: NR). NR exhibits a strong environment-dependent blue shift, a high quantum yield and low fluorescence in water $(19,20)$. The fluorescence spectra were measured using a fluorescence spectrophotometer (model F-4500, Hitachi Co., Ltd., Tokyo, Japan) upon excitation at $549 \mathrm{~nm}$ at $25^{\circ} \mathrm{C}$. The micropolarity of NR incorporated into the lipid aggregates was evaluated using the wavelength of maximum intensity of emission. A $3.8 \mathrm{mg}$ of NR was dissolved in $10 \mathrm{ml}$ of acetone $(100 \mu \mathrm{M})$. Five microliters of each solution were then diluted with $5 \mathrm{ml}$ of $10 \mathrm{mM}$ of E5880 aqueous solutions, methanol, ethanol, propanol, butanol, isobutanol, acetone, tetrahydrofuran and acetnitorile, respec- 
tively. The wavelengths at the maximum fluorescence intensity of each solution was plotted against the polarity of each solvent (21). The micropolarity around the probe was determined using this standard curve.

\section{Results and Discussion}

\section{$3 \cdot 1$ Critical Micelle Concentration}

Figure 2 shows the surface tension at the E5880 solution-air interfaces $\gamma$ as a function of the E5880 concentrations in the solution $C$. The $\gamma$ value at $C=0\left(\gamma_{0}\right)$ was $72.0 \mathrm{mN} / \mathrm{m}$ at $25^{\circ} \mathrm{C}$. The $\gamma$ value of the $\mathrm{E} 5880$ solution falls abruptly in the concentration 0.08-0.1 $\mathrm{mg} / \mathrm{ml}$ and was constant at the concentration above 0.09 $\mathrm{mg} / \mathrm{ml}$. This indicates that the critical concentration for formulation of the micelle was $0.09 \mathrm{mg} / \mathrm{ml}$. The adsorption amount at the surface $\Gamma\left(\mathrm{mole} / \mathrm{cm}^{2}\right)$ is correlated with the change of surface tension $(\mathrm{d} \gamma / \mathrm{d} \ln C)_{T, P}$ by the Gibbs adsorption equation:

$$
\Gamma=-(1 / 2 R T) \cdot(\mathrm{d} \gamma / \mathrm{d} \ln C)_{T, P}
$$

Here, $R$ is the gas constant. Figure 3 shows the adsorption amounts $\Gamma$ calculated using Eq. 1 as a function of the concentration of E5880. The surface pressure of the lipid monolayer $F$ is calculated as

$$
F=\gamma_{0}-\gamma
$$

Surface area per lipid molecule (molecular area) $A$ is evaluated as $A=1 /\left(N_{A} \Gamma\right)$

Here, $N_{A}$ is the Avogadro number. Figure 4 shows the

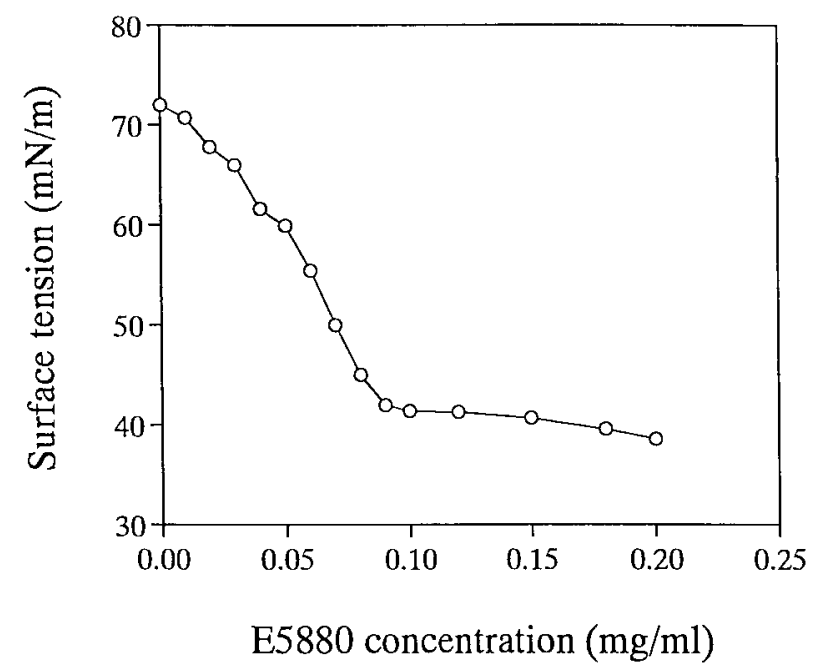

Fig. 2 Surface Tension at Air-Solution ( $0.1 \%$ citric acid, $10 \%$ lactose, $\mathrm{pH} 2.8$ ) Interface as a Function of the E5880 Concentration at $25^{\circ} \mathrm{C}$.

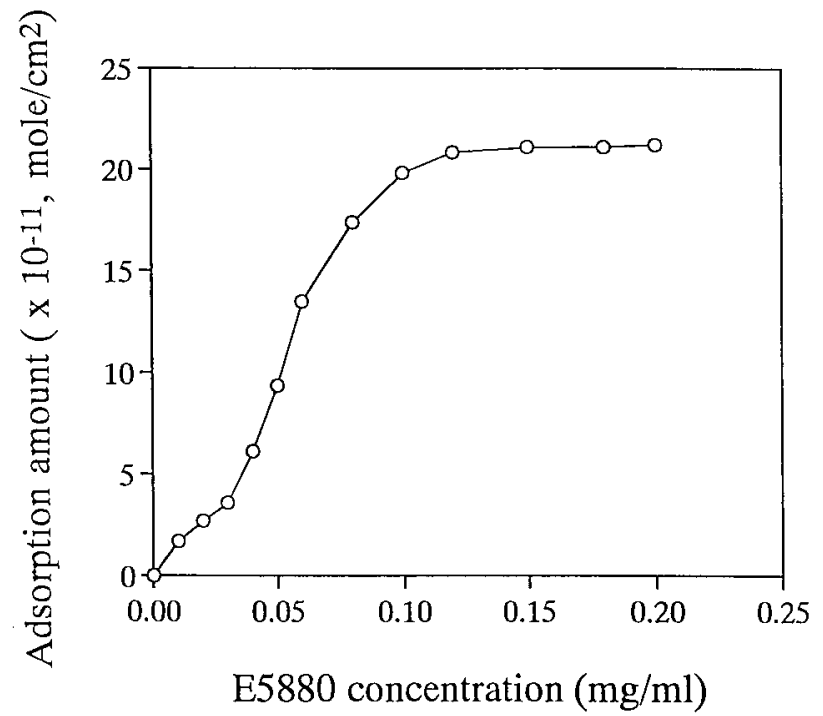

Fig. 3 Adsorption Isotherms of E5880 at Air-Solution $(0.1 \%$ citric acid, $10 \%$ lactose, $\mathrm{pH} 2.8)$ Interface as a Function of the E5880 Concentration at $25^{\circ} \mathrm{C}$.

surface pressure-molecular area curves ( $F-A$ curves) for the lipids. The limiting area for E5880 was $0.90 \mathrm{~nm}^{2}$.



Fig. 4 Surface Pressure-Molecular Area Curves of E5880 at Air-Solution $(0.1 \%$ citric acid, $10 \%$ lactose, $\mathrm{pH}$ 2.8) Interface as a Function of the E5880 Concentration at $25^{\circ} \mathrm{C}$. 


\section{$3 \cdot 2$ Determination of the Micellar Struc- ture by Calculation of the Critical Packing Parameters}

The critical packing parameters (22) for E5880 were calculated based on the area per molecule results (Fig. 5), the volume of the hydrophobic part, and the length of the acyl chain. For the formation of closed lamellar bilayer structures, the effective cross section of the hydrocarbon moiety must be lower than that of the hydrophilic head group region. This assumption is confirmed by an estimation of the critical packing parameter according to the formula (23) $x=v / a \cdot l$ ( $v$ is the volume of the hydrophobic part, $a$ is the area of the hydrophilic head group, and $l$ is the length of the acyl chain). When $x<1 / 3$, spherical micelles form; at $1 / 3<$ $x<1 / 2$, tubular micelles form; at $1 / 2<x<1$, vesicles form; and at $1<x$, hexagonal $\mathrm{H}_{\text {II }}$ structures form. The volume of the hydrocarbon domain $v$ and the length of hydrocarbon $l$ were calculated using the following equations:

$$
\begin{aligned}
& v=(27.4+26.9 n) \times 10^{-3}\left(\mathrm{~nm}^{3}\right) \\
& l=(0.15+0.1256 n)(\mathrm{nm})
\end{aligned}
$$

Where $n$ represents the number of the carbons for hydrocarbon chains. For E5880, $v=0.51\left(\mathrm{~nm}^{3}\right), l=2.4$ (nm), $a=0.90\left(\mathrm{~nm}^{2}\right)$, and $x=0.24$. Therefore, it can be expected that E5880 forms spherical micelle structure. The number of molecules in the spherical micelles $N$ can be calculated by the following equations (22):

$$
N=36 \pi v^{2} / a^{3}
$$

For E5880, $N=40$.

\section{3·3 Determination of the Molecular Weight of the E5880 Micelles}

The refractive index increments $(\mathrm{d} n / \mathrm{d} c)$ of the micelles were $0.15 \mathrm{ml} / \mathrm{g}$. Table 1 shows the molecular weight of E5880 micelles, $3.96 \times 10^{4}$. The molecular



Fig. 5 Relationship between Solvent Polarity and Emission Maximum of Nile Red $(100 \mathrm{nM})$ at $25^{\circ} \mathrm{C}$. 1: methanol, 2: ethanol, 3: propanol, 4: butanol, 5: isobuthanol, 6: acetone, 7: tetrahydrofuran, 8: acetnitorile.

weight of E5880 molecule is 861.6 and using these values, the number of molecular per micelle can be calculated and shown in Table $1(N=46)$ and similar to that calculated by critical packing parameter $(N=40)$.

\subsection{Determination of the Size and Zeta Potential of E5880 Micelles}

Table 1 shows the size and the zeta potential of E5880 micelles ( $\mathrm{pH} 2.8$ ). The weight-average diameter for E5880 micelles was $5.6 \mathrm{~nm}$. This value was good agreement with the ones calculated using the 'critical packing parameters' $(4.8 \mathrm{~nm})$. The zeta potential of the micelles ( $\mathrm{pH} 2.8$ ) was $+6.3 \mathrm{mV}$. The positive charge of the head group of E5880 is thought to be responsible for the positive value of the zeta potential of E5880

Table 1 Characterization of E5880 Micelles in the Formulation.

\begin{tabular}{ll}
\hline Size $(\mathrm{nm})$ & $5.6 \pm 4.1$ \\
Zeta potential & $+6.3 \pm 1.2$ \\
Critical micelle concentration $(\mathrm{mg} / \mathrm{ml})$ & 0.09 \\
Critical packing parameter & 0.24 (spherical micelle) \\
Molecular weight & $3.96 \times 10^{4}$ \\
The number of molecules/micelle & 46 \\
Emission maximum of NR (nm) & 621 \\
Micropolarity around the hydrocabon & Similar to that of isobuthanol \\
region in the micelle & (emission maximum of isobuthanol: $622 \mathrm{~nm}$ )
\end{tabular}


micelles.

\subsection{Determination of the Micropolarity around Nile Red in the Hydrocarbon Region in the E5880 Micelles}

The micropolarity of hydrocarbon regions in E5880 micelles was determined using a fluorescence technique (probe: Nile Red, NR). NR exhibits a strong environment-dependent blue shift, a high quantum yield and low fluorescence in water $(19,20)$. The fluorescence spectra were measured using a fluorescence spectrophotometer (model F-4500, Hitachi Co. Ltd., Tokyo, Japan) upon excitation at $549 \mathrm{~nm}$ at $25^{\circ} \mathrm{C}$. The micropolarity of NR incorporated into the lipid aggregates was evaluated using the wavelength of maximum intensity of emission $(19,20)$.

Figure 5 shows the relationship between solvent polarity (21) and emission maximum of NR at $25^{\circ} \mathrm{C}$. The emission maximum of E5880 micelles was 622 $\mathrm{nm}$, indicating that the micropolarity around the probe in the lipid aggregates is comparable to that of isobutanol $(621 \mathrm{~nm})$.

\section{References}

1. D.J. HANAHAN, Platelet Activating Factor: A Biological Active Phosphoglycerid, Annu. Rev. Biochem., Vol. 55, 483-489 (1986).

2. J. BENVENISTE, P.M. HENSON and C.G. COCHRANCE, Leukicyte-Dependent Histamine Release from Rabbit Platelets. The Role of IgE, Basophilis, and a Platelet-Activating Factor, $J$. Exp. Med., Vol. 136, 1356-1377 (1972).

3. J.O. SHAW, R.N. PINCKARD, K.S. FERRIGNI, L.M. McMANUS and D.J. HANAHAN, Activation of Human Neutrophilis with 1- $O$-hexadecyl/octadecyl/, 2-acetyl-sn-glycerol-3phosphorylcholine (platelet activating factor), J. Immunol., Vol. 127, 1250-1255 (1981).

4. B.B. VARGAFTIG, J. LEFORT, M. CHIGNARD and J. BENVENISTE, Platelet-Activating Factor Induces a Platelet-Dependent Bronchoconstriction Unrelated to the Formation of Prostagrandin Derivatives, Eur. J. Pharmacol., Vol. 65, 185-192 (1980).

5. D.M. HAMPHREY, L.M. McMANUS, K. SATOUCHI, D.J. HANAHAN and R.N. PINCKARD, Vasoactive Properties of Acetyl Glyceryl Phosphorylcholine and Analogues, Lab. Invest., Vol. 46, 422-427 (1982).

6. M.L. BLANK, F. SNYDER, L.W. BYER, B. BROOKS and E.E. MUIRHEAD, Antihypertensive Activity of an Alkyl Ether Ana$\log$ of Phosphatidylcholine, Biochem. Biophys. Res. Commum., Vol. 90, 1194-1200 (1979).

7. P. BESSIN, J. BONNET, D. APFFEL, C. SOULARD, L. DES-
GROUX, I. PELAS and J. BENVENISTE, Acute Circulatory Collapse Caused by Platelet-Activating Factor (PAF-acether), Eur. J. Pharmacol., Vol. 86, 403-413 (1982).

8. S. SAEKI, F. MASUGI, T. OGIHARA, A. OTSUKA, Y. KUMAHARA, K. WATANABE, K. TAMURA, A. AKASHI and A. KUMAGAI, Effect of A-O-alkyl-2-acetyl-sn-glycero-3phosphocholine (platelet activating factor) on Cardiac Function in Perfused Guinea-Pig Heart, Life Sci., Vol. 37, 325-329 (1985).

9. S. OH-ISHI, K. YAMAKI, M. HAYASHI, S. TSUSHIMA and H. NOMURA, Suppression of Phorbol Myristate AcetateInduced Pleurisy by CV-3988, Chem. Pharm. Bull., Vol. 34, 4896-4898 (1986).

10. Y. IMURA, Z. TERASHITA and K. NISHIKAWA, Possible Role Platelet Activating Factor (PAF) in Disseminated Intravascular Coagulation (DIC), Evidenced by Use of a PAF Antagonist, Life Sci., Vol. 39, 111-117 (1986).

11. H. TAKIZAWA, A. ISHII, S. SUZUKI, J. SHIGA and T. MIYAMOTO, Bromchoconstriction Induced by Platelet-Activating Factor in the Guinea Pig and Its Inhibition by CV-3988, a PAF Antagonist: Serial Changes in Findings of Lung Histology and Bronchalveolar Lavage Cell Population, Appl. Immunol., Vol. 86, 375-382 (1988).

12. Z. TERASHITA, S. TSUSHIMA, Y. YOSHIDA, H. NOMURA, Y. INADA and K. NISHIKAWA, CV-3988 - a Specific Antagonist of Platelet Activating Factor (PAF), Life Sci., Vol. 32, 19751982 (1983).

13. Z. TERASHITA, Y. IMURA, M. TAKATANI, S. TSUSHIMA and K. NISHIKAWA, CV-6209, a Highly Potent Antagonist of Platelet Activating Factor in vitro and in vivo, J. Pharmacol. Exp. Ther., Vol. 242, 263-268 (1987).

14. D.A. HANDLEY, R.G. Van VALEN, M.K. MELDEN, S. FLURY and M.L. Lee, Inhibition and Reversal of Endotoxin-, Aggregated IgG- and PAF-Induced Hypotension in the Rat by SRI 63-072, a PAF Receptor Antagonist, Immunopharmacology, Vol. 12, 11-16 (1986).

15. A. TOKUMURA, H. HOMMA and D.J. HANAHAN, Structural Analogs of Alkylacetylglycerophosphocholine Inhibitory Behavior on Platelet Activation, J. Biol. Chem., Vol. 260, 12710-12714 (1985).

16. J. NAGAOKA, K. HARADA, A. KIMURA, S. KOBAYASHI, M. MURAKAMI, T. YOSHIMURA, K. YAMADA, O ASANO, K. KATAYAMA and I. YAMATSU, Inhibitory Effects of the Novel Platelet Factor Receptor Antagonist, 1-ethyl-2-[N(2-methyl)benzoyl-N-[(2R)-2-methyl-3-(4-octadecylcarbamoyloxy)piperidinocarbonyloxypropyloxy]carbonyl]aminomethylpyridinium Chloride, in Several Experimentally Induced Shock Models, Arzneimittel-Forschung Drug Res., Vol. 41, 719-724 (1991).

17. Y. SANO, Characterization of Sizes of L- $\alpha$-phosphatidylcholine Liposomes, Bull. Natl. Inst. Agrobiol., Vol. 3, 1-9 (1987).

18. E. GULARI, E. GURALI, Y. TSUNASHIMA and E. CHE, Photon Correlation Spectroscopy of Particle Distribution, J. Chem. Phys., Vol. 70, 3965-3972 (1979).

19. P. GREENSPAN and S.D. FOWLER, Spectrofluorometric Stud- 
ies of the Lipid Probe, Nile Red, J. Lipid Res., Vol. 26, 780-791 (1985).

20. D.L. SACKETT and J. WOLF, Nile Red, as a Polarity-Sensitive Fluorescent Probe of Hydrophobic Protein Surfaces, Anal. Biochem., Vol. 167, 228-234 (1987).

21. K. DIMORTH and C. REICHARDT, Uber PyridinumphenalBetaine und Ibre Verwendung Zur Charakteriserung der Polarität von Lösungsmitteln, Liebig, Ann., Vol. 661, 1-37 (1963).

22. J.N. ISRAELACHIVILI, S. MARCEIJA and R.G. HORM, Physical Principles of Membrane Organization, Q. Rev. Biophys., Vol. 13, 121-200 (1980).

23. J.N. ISRAELACHIVILI, D.J. MITCHELL and B.W. NINHAM, Theory of Selfassembly of Lipid Bilayers and Vesicle, Biochim. Biophys. Acta, Vol. 470, 185-201 (1977). 